This is the author's manuscript for publication. The publisher-formatted version may be available through the publisher's web site or your institution's library.

\title{
Understanding vision: students' use of light and optics resources
}

Dyan L. Jones and Dean Zollman

\section{How to cite this manuscript}

If you make reference to this version of the manuscript, use the following information:

Jones, D. L., \& Zollman, D. (2014). Understanding vision: Students' use of light and optics resources. Retrieved from http://krex.ksu.edu

\section{Published Version Information}

Citation: Jones, D. L., \& Zollman, D. (2014). Understanding vision: Students' use of light and optics resources. European Journal of Physics, 35(5), 055023.

Copyright: (C) 2014 IOP Publishing Ltd

Digital Object Identifier (DOI): doi:10.1088/0143-0807/35/5/055023

Publisher's Link: http://iopscience.iop.org/0143-0807/35/5/055023

This item was retrieved from the K-State Research Exchange (K-REx), the institutional repository of Kansas State University. K-REx is available at http://krex.ksu.edu 


\author{
Understanding Vision: Students' Use of Light and Optics Resources \\ Dyan L. Jones ${ }^{1}$ and Dean Zollman ${ }^{2}$ \\ 1. Mercyhurst University, Erie PA 16546 \\ 2. Kansas State University, Manhattan KS 66056
}

\begin{abstract}
We present a qualitative study designed to examine how students construct an understanding of the human eye and vision from their knowledge of light and optics. As would be expected, vast differences are shown to exist between pre- and post-instruction students in terms of not only resource use, but also willingness to transfer their existing knowledge. However, we have found that appropriate scaffolding can facilitate resource activation and guide students to construct an understanding of vision and vision defects.
\end{abstract}

\title{
I. INTRODUCTION
}

Many physicists see a natural connection between the principles of light and geometric optics and the function of the human eye. Even a quick look at the existing literature, though, indicates that these connections may not be so apparent to students, even after extensive time and coursework on the subject. Still, many physics teachers feel that this is a worthwhile and even necessary application of the theory to share with students. As such, this study was conducted to investigate, in detail, students' reasoning as they apply ideas about light and optics and as they attempt to translate those ideas into an understanding of vision and vision defects. The study was conducted in a series of phases, enabling us to observe a wide variety of student reasoning patterns. Data include both qualitative interviews and surveys, and students were interviewed both pre- and post-instruction in traditional and research-based learning environments.

The main research questions guiding the entire study are: What resources do students use when constructing an understanding of vision and vision defects, and how do they transfer their existing knowledge about light and optics in the process?

\section{LITERATURE REVIEW}

Research has been conducted on student conceptions of light and optics with students of many ages - from elementary school through college - and in countries all across the world. Because it would be impossible to present all of the literature that exists on this topic, the following presents a representative sample of previous research in the field.

\section{A. Student understanding of light and optics}

Though we have constant, everyday experiences with light, researchers have shown that young students do not have a consistent understanding of the physical properties of light. For example, Andersson and Karrqvist ${ }^{1}$ looked at the notion of light as existing as a physical object and Stead and Osborne ${ }^{2}$ investigated the perception of light traveling different distances during the day and night. At the upper-level high school and undergraduate levels, research has also been conducted on how students understand and apply the basic physical properties of light. Langley et al. ${ }^{3}$ showed that while students had some familiarity with optical systems, they were confused by a unified model of optics in which the context of sight was discussed. Saxena ${ }^{4}$ found that while students seemingly understood the basic properties of light, they were unable to apply that knowledge to real situations. While studying prospective elementary teachers, Bendall et al. ${ }^{5}$ found that they were unable to successfully complete tasks that focused on the propagation of light.

A separate and equally large body of literature exists on student understanding of lenses and ray optics. Goldberg and McDermott ${ }^{6}$ found that students had two major barriers to understanding how images were formed by a plane mirror: the first is the belief that an image can only be seen if it lies along the line-of-sight of the object, and the second is a lack of understanding of where the observer is located with respect to ray diagrams. In a later study, Goldberg and McDermott examined student conceptions dealing with images formed by converging lenses ${ }^{7}$. They found similar difficulties with interpreting ray diagrams and the role of the observer, as well as a dependence on naïve conceptions of light even in post-instruction participants. Galili et al. ${ }^{8}$ found a similar result, calling students' conceptualization of image formation a "projected-image conceptualization ... a hybridization of their pre-instruction holistic conceptualization and the formal physics conceptualization". 
The body of literature on student understanding of physical optics is much smaller than that for geometric optics. However, Ambrose and colleagues ${ }^{9}$ conducted studies on student understanding of some wave phenomena of light. One study focused on the formation of diffraction and interference patterns, and found that students had difficulty knowing whether to apply geometric or wave optics, and as such often incorrectly applied pieces of each. Thus, this and other studies on college-aged students indicate students inappropriately transfer learning to explain some of the optical phenomena.

\section{B. Methods of teaching light and optics}

Based on the volume of literature about student difficulties with light and optics, it is no surprise that the literature also contains a great number of articles about how and when optics should be taught. The following are just a sample of ideas, chosen with the intention of highlighting the wide range that exists.

To deal with the difficulties that arise because of the use of ray diagrams, one suggestion is to use many rays, and therefore highlight the notion that light spreads out in many directions from a single point ${ }^{10}$. Following previous work on designing Tutorials in Introductory Physics ${ }^{11}$, Wosilait et al. ${ }^{12}$ created a research-based tutorial that focuses on light and shadows. The Active Learning in Optics and Photonics (ALOP) ${ }^{13}$ program is an initiative to promote the inclusion of optics in introductory courses. Other works have used optics as a context for studying teaching methods in general. For example, the utilization of history is illustrated by Galili ${ }^{14}$, and Stephenson and Warwick ${ }^{15}$ demonstrated the utility of concept cartoons for eliciting alternative conceptions about light.

A subsection of the above-proposed activities include the extensive use of computer simulations for teaching light and geometric and physical optics. The perceived benefits included a vivid visual representation, the ability to continue examining phenomena outside of a laboratory setting, and the shorter time frame in which the concepts could be displayed ${ }^{16}$. As computers became more accessible, research-based software began to appear. Eylon et al. ${ }^{17}$ created a learning environment known as RAY with features such as ray-tracing and graphic tools and found that, while using the simulation improved how often students correctly used the ray model of light, it did not have a significant effect on measured conceptual understanding of light as a whole. Goldberg and Bendall ${ }^{18}$ also developed a computer learning environment for teaching optics and showed that while more time is required for the computer visualization than for traditional instruction, students had a positive experience and tended to increase their active engagement in the learning process.

Whether and how to deal with the human eye when teaching optics is also well-discussed in the literature, though few of such claims are substantiated by research. Jones ${ }^{19}$ asserts that we must be careful when deciding whether to use the human eye as a teaching tool in optics, because it may not aid understanding. Conversely, Ronen and Eylon ${ }^{20}$ argue that incorporating a functional model of the human eye throughout the learning process can lead to an increased understanding of optics principles.

Methods for teaching the human eye in the context of optics include using the blind-spot of the human eye to learn about image formation ${ }^{21}$ and utilizing pinholes and converging lenses successively to progress toward an understanding of the eye ${ }^{22}$. Specific suggestions for experiments also exist, for example from Edwards et al. $^{23}$, in a three-part article by Mullin ${ }^{24}$, and by Arell and Kolari ${ }^{25}$, to name just a few. Many of the above claims, while interesting, have no published measures of success or hardships as determined by research, and as such they were not used to inform this study.

A research-based lesson on accommodation was developed by Wiesner et $\mathrm{l}^{26}$. This lesson uses inexpensive materials to teach students about the process of accommodation in human vision. Two computer visualization created as part of this lesson are also available ${ }^{27}$. Interest in the optics of the eye seems to have again resurfaced recently. Another lesson on the accommodation of eyes was created by Dilek and $\mathrm{Sahin}^{28}$, who created two simple demonstrations for this purpose. Kaltakci and Eryilmaz focsed on a variety of animal eyes, in a way similar to the end result of this research project ${ }^{29}$. This push toward applying the physics of optics to the biology is highlighted by Brewe $^{30}$ who explicates the need to integrate physics and biology teaching and learning.

\section{Resources and Transfer of Learning}

Hammer uses the term 'resource' to describe in general the different constructs that students use when developing their knowledge ${ }^{31}$. Resources may be of varying grain-sizes, though they are always small in that they do not constitute a complete model. Instead, resources can be thought of as a piece of "raw intuition" 32 that can be applied in a wide range of situations. Resources include a range of phenomenological, epistemological or procedural concepts. They cannot be labeled as correct or incorrect; instead, the activation of appropriate resources for the given context or situation is important. The activation/association of resources can easily be tied into the transfer of learning framework that will be discussed in the following sections. 
Along with the identification of resources, Hammer et al. ${ }^{33}$ assert that one must also consider the context in which the resources are activated, as well as how the student frames the situation. The way a student interprets a given task or situation is known as 'framing'; two different students could potentially frame the same situation in very different ways. For example, if a student frames the situation as one in which knowledge must be given by authority, the student will likely be hesitant to create and test new ideas. In this respect, the way that the student frames a situation can affect what resources are activated or deactivated and must be carefully considered along with the resources themselves.

We also sought to identify what phenomenological primitives (p-prims) were used by students during this study ${ }^{34}$. P-prims are the smallest and perhaps simplest grain-size of knowledge, and are applicable in a wide range of contexts and situations ${ }^{35,36}$. The name phenomenological primitive is significant because it classifies these structures as simple, concrete, and derived from the observations and experiences of the individual.

The study of transfer is one that has been evolving for a few decades, with the earliest studies of transfer focused primarily on examining if and how students were able to apply previously learned problem solving techniques in new but structurally similar situations ${ }^{37}$.

This work presented here adopts the contemporary perspectives of transfer and seeks to consider all prior knowledge and information that students use when constructing new knowledge. These contemporary perspectives shifted away from identification of similarities that, according to experts, should transfer. Instead, researchers began observing any and all knowledge that could potentially transfer to a new situation. Based on the idea of situated learning ${ }^{38}$, Lobato ${ }^{39}$ presented what she dubbed an "actor-oriented" view of transfer - this allowed for similarities to be defined by the student instead of the expert. As others continued forward with this broadened definition, transfer became thought of as being universal - everyone transfers some information into every new situation.

Bransford and Schwartz ${ }^{40}$ look at transfer as being a measure of how prepared students are for future learning endeavors; they discuss evaluation as being either sequestered problem solving, which measures the traditional transfer, or preparation for future learning, which allows for the measurement of transfer from a more contemporary stance. They also describe a difference between information that is transferred into and transferred out of a given situation, and highlight a need to examine transfer in both the learning and application contexts.

Rebello and colleagues ${ }^{41}$ emphasize the need to describe transfer from the perspective of the student instead of the researcher/expert. In this perspective, transfer is a dynamic process in which the students create associations between pieces of knowledge to understand some target phenomenon. Because they are in a new situation, the students must create associations between pieces of their preexisting knowledge structure and the new information that they are obtaining from their environment.

\section{METHODOLOGY}

Our study used a mixed methodology designed to investigate how students understand light and optics in the context of the human eye and vision. Data were collected through a series of one-on-one clinical interviews, learning/teaching interviews (see the next section), and in-class implementations, then analyzed to elicit student resource use. The following section details the collection and analysis of the data.

\section{A. Model and Apparatus}

To activate and study dynamic transfer, we provided participants in the first learning/teaching interview with a set of experiences that allowed them to develop conceptual resources which could be used to build an understanding of lenses, the human eye, and vision. 


\section{Light rays in the eye}

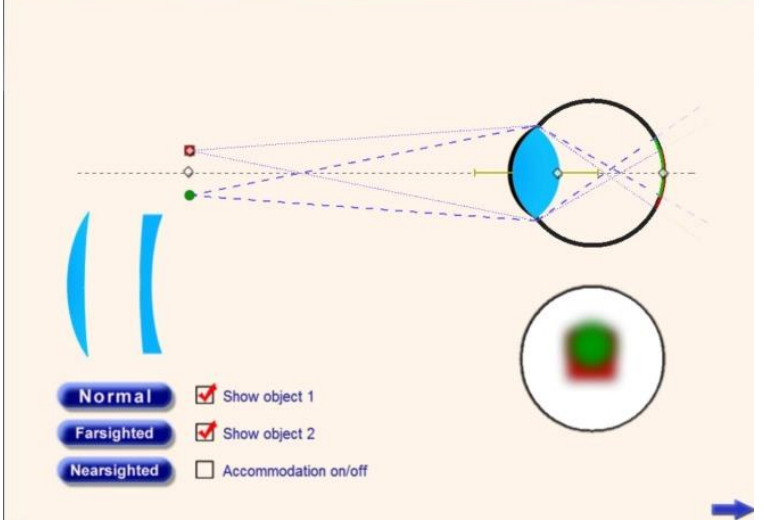

\section{Light rays in the eye

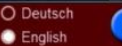

Figure 1 Screen shots of the computer simulation used during the first interview

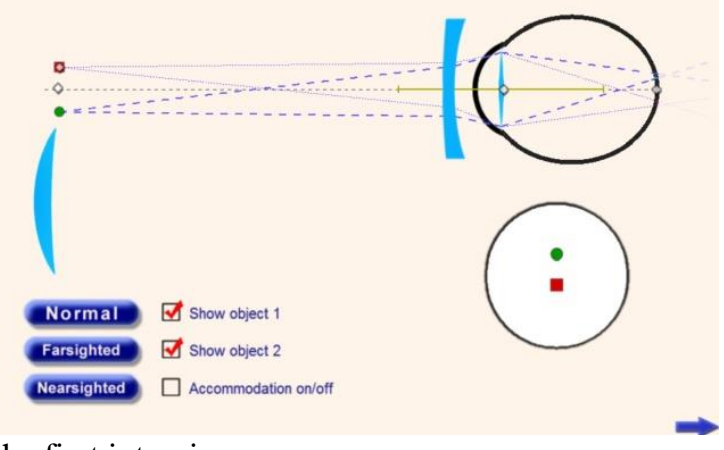

A series of hands-on learning experiences facilitated a progressive development of a model of the human eye through activating and coordinating appropriate resources. Students started with a fixed-focus lens and continued through learning about accommodation of the eye lens. Students also discussed vision defects such as farsightedness and nearsightedness and the lenses used for correction. The hands-on activities included two components: a computer visualization (Figure 1) and a physical model of the eye (Figure 2), both which were used in combination throughout the interview. The computer visualization allowed students to manipulate several parameters including: the shape of the eye to simulate near- and far-sightedness, the thickness of the lens inside the eye, the addition of corrective lenses outside the eye, and the ability of the eye to automatically accommodate for varying object distances. The visualization had the further advantage of providing a sort of ray diagram that indicated the location of the focal point. The model allows students to physically manipulate many of the same variables shown in the visualization such as the object distance, the eye shape, and also to adjust the level of accommodation of the eye lens and directly observe the resulting effects ${ }^{42}$. The feature of primary importance in our model is the ability to demonstrate the accommodating lens of the eye by adjusting the amount of water (and therefore the thickness) of a small bladder. Further, an array of small lenses (made in-house) was placed in front of the eye model to allow for a more in-depth look at the vision defects of the eye. A small light, for example a miniature LED flashlight as was used to create the figure below, can be used to illuminate the eye and lens array. When free of defects, the light will shine directly through the lens array and create points of light in a uniform grid pattern. When the eye is defective, however, this grid pattern will shift and become distorted (see Figure 2).
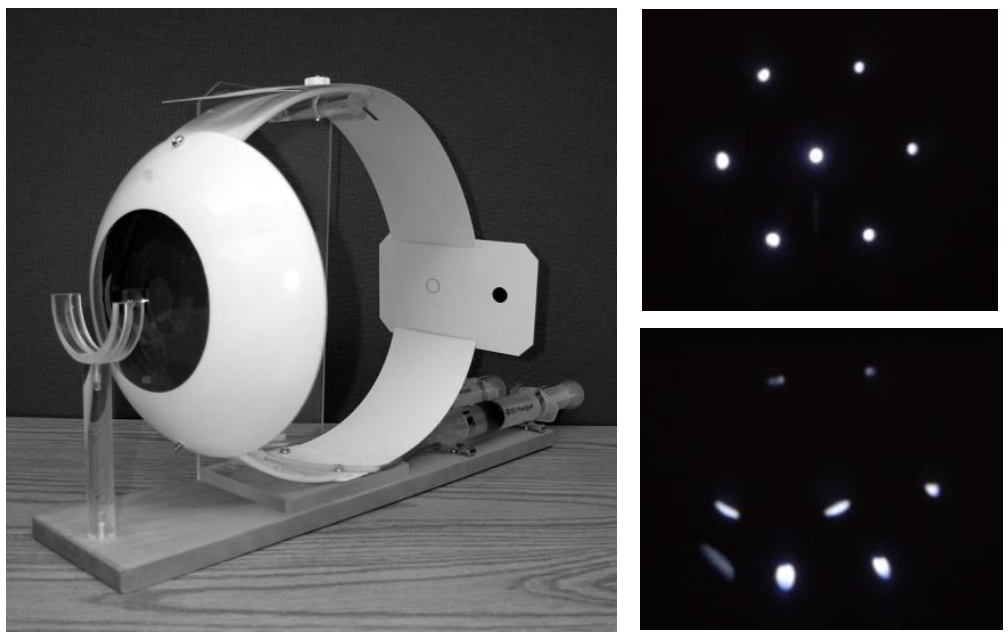
While

Figure 2 The eye model, and the Grid pattern formed by lens array

the simulation allowed for the manipulation of the same variables, it had the added feature of visible ray diagrams. For example, students could find the focal point - a clear image, as shown in the model - but also see what the focal point signified in terms of the light rays intersecting. It also allowed students to see easily if the focal point was in front of or behind the retina in the case of vision defects.

\section{B. Data collection and Sample}

A combination of four sub-sections (or phases) makes up the total set of data presented here. Initially, students were interviewed individually to determine how they understood the basics of light, optics, the human eye, and vision. Using these results, a learning/teaching protocol was then developed to guide students through a progressive understanding of the human eye and vision. A learning/teaching interview ${ }^{43}$ is a form of mock-instruction in which the researcher is also the facilitator of learning. Learning/teaching interviews provide a rich context in which the researcher can observe the dynamic learning process by asking follow-up and probing questions and providing scaffolding as necessary.

The data for this study were collected over two years and consisted of four subsections of volunteer introductory-level university students, all of which were mutually exclusive. The participants in this study were students at a large university in the Midwestern USA. The students were enrolled in introductory-level courses - Table 1 indicates for each phase of the study whether they were pre- or post-instruction in optics when they participated. The participants were chosen by convenience sampling; all students from a course were solicited to be volunteers, and those whose schedules allowed for an interview time were chosen. Gender distribution in the sample matched the university distribution - nearly 50/50. Demographics such as year in school and major were not considered as the more important qualification was that all students were enrolled in an introductory course.

The characteristics of each subset are described in Table 1; the phases and are ordered chronologically, and include the number of participants in each set, whether the students had received classroom instruction in basic light and optics before being interviewed, the number of interviews and what was discussed, and the label used to identify the group in the results and discussion section to follow.

Table 1 Breakdown of each phase of the study

\begin{tabular}{|l|l|l|l|}
\hline Participants & Instruction & Data collection & Subset Label \\
\hline 12 & Pre-instruction & Interview 1 - Light and Optics & $\begin{array}{l}\text { Pre-Instruction } \\
\text { Individuals }\end{array}$ \\
\hline 155 & $\begin{array}{l}\text { Post-instruction, } \\
\text { traditional lecture }\end{array}$ & Open-ended responses to Qualitative Survey & $\begin{array}{l}\text { Qualitative } \\
\text { Survey }\end{array}$ \\
\hline 18 & Pre-instruction & $\begin{array}{l}\text { Interview 1 - Exploring light and optics } \\
\text { Interview 2 - Learning/Teaching Vision }\end{array}$ & $\begin{array}{l}\text { Research- } \\
\text { based- } \\
\text { Instruction } \\
\text { Individuals }\end{array}$ \\
\hline $\begin{array}{l}13 \\
(5 \text { groups })\end{array}$ & $\begin{array}{l}\text { Post-instruction, } \\
\text { research-based } \\
\text { learning materials }\end{array}$ & Interview 1 - Learning/Teaching Vision & $\begin{array}{l}\text { Post- } \\
\text { Instruction } \\
\text { Groups }\end{array}$ \\
\hline
\end{tabular}

\section{Data analysis}

The data were analyzed using grounded theory ${ }^{44}$ and phenomenographic ${ }^{45}$ approaches to examine the variations in student ideas and detect themes. Specifically, this work presents a resource-analysis of the data.

In general, student responses were coded to identify the resources that they were using when constructing their understanding and to examine how they were activating and associating the resources while constructing an understanding of the human eye. In this case, we are using the definition of "resource" provided by Hammer in his multiple works ${ }^{32}$. Inter-rater reliability studies were conducted on sample data, and a result of $94 \%$ reliability between 3 raters after a single discussion was obtained.

Of particular interest is the context surrounding the use of each resource ${ }^{32}$, such as how and when, and often times in what order certain resources are activated. Similar themes emerged across all phases of the study; those common threads are highlighted in the following sections. 


\section{RESULTS AND DISCUSSION}

Each subsection of the study was slightly different from the others because of the natural progression of any research project. Some differences include pre- versus post-instruction, individuals versus groups, and verbal versus written responses. Interesting emergent themes from each of these cases are presented when available. This section presents the results chronologically as they were completed in the study. As with all large qualitative studies, it is impossible to present all of the data that is systematically collected; as such, the following is a representative sample of the data obtained. More complete data can be obtained by contacting the corresponding author and also in the dissertation on this work ${ }^{46}$.

\section{A. Pre-Instruction-Individuals - Interviews}

During the first portion of the interview, students were asked to describe how the human eye worked. One major trend in the data is that students describe the eye as being a two-part system, comprised of a lens and a screen (the retina). This is evident not only in their verbal responses, but also in the sketches that they draw. For example, see Figure 3. Very few students initially mentioned other parts such as the iris, cornea, etc.

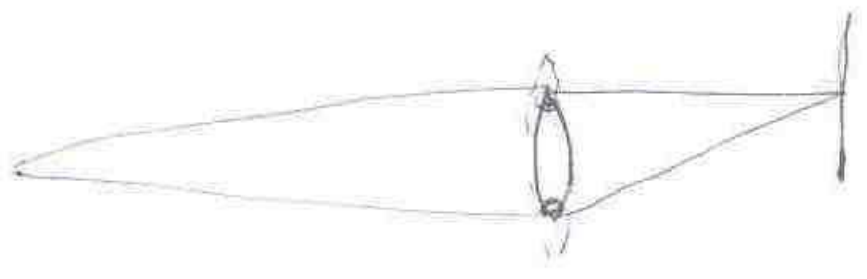

Figure 3 Student sketches of light entering the eye

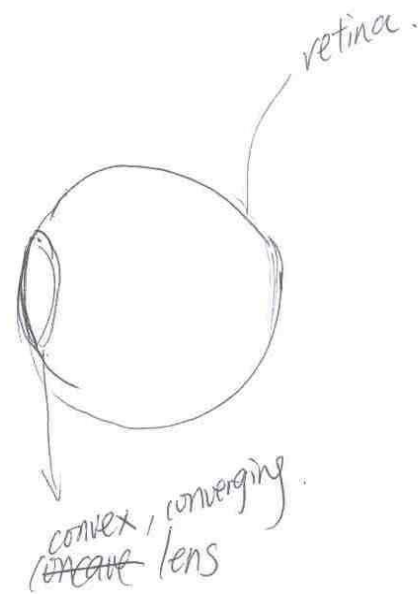

When asked about vision defects, fewer than half of the participants could explain near- and farsightedness. Of those who could accurately describe the defects, the vast majority indicated that they had corrective lenses for a vision defect. Most of the students felt that the problems resulted from a defect in the lens of the eye, and made no mention of the shape of the eye. In general, knowledge of the human eye varied widely among students, and did not seem to depend on their level of schooling. This realization guided the rest of the project in that all students who were interviewed from this point forward had a concept introduction of some sort on the topics of basic optics and the human eye before the discussion moved to vision defects.

\section{Light Moves as a Straight Line}

The first resource, light can be represented by a line, was extracted partially from statements from participants, but mostly from their sketches. Of the 12 participants, nine made sketches similar to ray diagrams and each clearly represented light as a straight line coming from a source, though students were never directly asked about the form of light. This resource, in reality, may be less than helpful or even hinder their understanding. When standing alone, the resource that light can be represented by a straight line is not at all inappropriate. However, if the students believe that light can only travel as a straight line, this could deter them from understanding that altered wavefronts are a result of vision defects.

Shape of Lens and Image Focus

Seven of the 12 participants indicated that the shape of a lens determined how/where the image was focused. For example, the following conversation is from the discussion about the model's accommodating lens: 
Student: "When I do this [add water to modify the shape of the lens], it changes the focus of the light." Interviewer: "Okay, how is it doing that?"

Student: "By, uh, changing the shape of the lens."

Another student explained the accommodating lens of the model in the following way:

"Well, this [increasing/decreasing the amount of water in the accommodating lens] changes the pressure the amount of fluid in here [the lens] - which would change the diameter of the lens, which would determine how focused something would be. Or, like that's how you focus [the lens]."

Again, this resource, which is a part of basic geometric optics, is useful for students in understanding that an image focuses and that the location of the focal point depends on the shape of the lens.

\section{Light through Lenses}

Perhaps most notable is the resource that light entering a lens differently will focus differently. This resource may in fact be based on a more basic p-prim that changing inputs causes a change in outputs, which can also be considered a basic cause-and-effect principle. This resource was activated by 10 of the 12 participants. For example, one student used the resource to explain the deformed grid pattern in the following way:

"Light wouldn't shine through the lens as clearly. It would be reflected in all different directions ... so now that you have a bending of the light, the focus [of the grid pattern] is just kind of messed up."

\section{B. Post-Instruction Individuals - Qualitative Survey}

The second phase of the study used the first phase to create a qualitative survey of the students' understanding of the components of the optics of vision. The results of this qualitative survey are summarized in Table 2, along with the question being answered in each case. Though the first two questions on the survey were technically different from the others in that one asked about the object moving away from the observer and the other asked about objects moving closer to the observer, all students answered in the same way for both questions, and therefore the responses listed are characteristic of both questions.

Table 2 Summary of results from qualitative survey. The most correct answer for each is in bold, the frequency is listed in parentheses.

\begin{tabular}{|c|c|}
\hline \multicolumn{2}{|c|}{ Q1/Q2 - Does the lens of the eye change to view objects at different distances? } \\
\hline Lens of the eye changes & $60 \%(93)$ \\
\hline Lens of the eye does not change & $13.5 \%(21)$ \\
\hline Other things in the eye change (focal point, iris, etc) & $20 \%(31)$ \\
\hline Lens of the eye moves & $6.5 \%(10)$ \\
\hline \multicolumn{2}{|l|}{ Q3 - Can the lens of the eye change shape? How? } \\
\hline Yes it can & $65.8 \%(102)$ \\
\hline Muscles make it change & $21.9 \%(34)$ \\
\hline No it cannot change & $27.7 \%(43)$ \\
\hline \multicolumn{2}{|l|}{ Q4 - What is needed to correct for defective lenses? } \\
\hline Converging or Diverging Lens is needed & $75.5 \%(117)$ \\
\hline Focal point needs to change & $11.6 \%(18)$ \\
\hline
\end{tabular}

As shown in Table 2, $80 \%$ of the students knew that something regarding the eye does change, and in fact only one student indicated that it was physically impossible for the lens to change, but $13.5 \%$ said that while it is possible for the lens to change, it does not do so in the given circumstances. Also interesting is the $6.5 \%$ of students who indicated that the lens of the eye actually moved, either forward or backward inside of the eye.

Question three directly asked "Can the lens in the eye change its shape? If yes, explain how these changes occur. If no, explain why it is not necessary." Only approximately one quarter of students said that it could not change shape, but none of them explained why it was not necessary. A total of $65.8 \%$ of students indicated that the lens of 
the eye could change shape. This includes the $21.9 \%$ who indicated that the change occurred because of muscles. Twenty percent of students answered in the affirmative, but with no explanation of how.

Finally, question four dealt with vision defects of the eye. Nearly $90 \%$ of students could indicate that corrective lenses were needed, but the above statistics do not account for whether the students assigned the converging/diverging lens to the appropriate defect.

Though the results of this qualitative survey do not exactly mimic the trends from the first set of interviews, one important result is clear: these students have a wide range of knowledge about the human eye, its functions, and vision defects. In many respects, students who had traditional instruction on the eye and lenses had a more predictable, though not flawless, understanding of the eye.

\section{Research-based-Instruction Individuals - Interviews}

Using the results of the previous two studies, we constructed two lessons on the optics of the human eye including appropriate research-based instructional methods and, primarily, hands-on activities which helped the students learn about the optics of the eye. The lessons can be downloaded from http://web.phys.ksu.edu/mmmm.

Illustrated again during this set of interviews was the wide variety of knowledge about the eye and vision that students have acquired. The following are the most significant and frequently used resources.

\section{Shape of the Eye and Image Focus}

The students often used the resource that the shape of the eye determines how well you can see, and continue using such a resource to say that if the shape changes, the focus change. In the first interview, scaffolding encouraged the students to use both the model and the computer simulation to learn how adjusting the distance from the retina to the lens thereby changes the shape of the eye. In particular, students were asked to discuss image quality and where the focal point was located with respect to the retina as they changed the length of the eye. Nearsightedness and farsightedness were explored in this manner. Therefore, the experiences provided during the first interview allowed the students to establish that the length of the eye - and therefore the distance from the retina to the lens - is a factor in how far away an object can be from the eye and still be in focus. Consider the following excerpt: perfect?"

Interviewer: "What do you think will happen to our grid pattern if the shape of the eye was not

Student: "You're looking at changing the distance, as far as the back of the eye ... it just goes handin-hand with the length of your eye. So if you move it [the retina] back, you're going to have to move this [the screen] either backward or forward, I just don't remember which."

This resource was then activated to create the idea that different eye shapes will make the grid focus at different distances. In total, 12 of the 18 participants accurately predicted that this change of focus would occur when the shape of the eye was changed; they were able to test their predictions to see that the change did indeed occur. Though the remaining six students did not correctly predict the occurrence, they did observe and comment on it during the prediction-testing stage.

To an expert, the above resource may sound more fundamental than described. Because the different shapes of the eye are in essence a variation of the distance between the 'lens' and 'screen' (retina), it could appear that the resource is actually dealing with the eye as an optical system. However, there is no way of knowing if the students are approaching the resource in this manner. In fact, many students used phrases which would indicate that they did not see this connection, such as saying that "long eyes make small grid patterns."

\section{Shape of the Eye and Image Size}

Students frequently use the smaller-grain resources known as phenomenological primitive (p-prim) when constructing understanding in new contexts ${ }^{36}$. The following is one example. perfect?"

Interviewer: "What do you think will happen to our grid pattern if the shape of the eye was not

Student: "It [retina] is further away, so it [focal point] has to be closer to here, so these [dots of grid pattern] are going to be smaller but brighter points, and when it [retina] is up here, they [dots of grid pattern] are going to be bigger fuzzier points."

In this case, the p-prim being used is that closer objects appear larger. This resource could have been activated from our everyday experiences, as things that are farther away from us appear to be smaller. However, this also could be seen with both the model and the simulation. As the object distance was increased, the changing image size was clearly visible. The transfer here is that different shapes of the eye will make the grid pattern appear larger or smaller. Half of the students ( 9 of 18) predicted that the size of the grid would change because of a differentlyshaped eye. 
The above resource can actually be viewed as a misapplication of a p-prim. In reality, the closer is bigger pprim is one that deals with perception - we perceive objects that are closer to us as being larger. As used above this resource exists within the context of optics because of the lens in the eye. Within the context of optics, a more appropriate resource might be that objects closer to a lens have larger images, though there are admittedly limitations of that resources if applied in all circumstances. However, the interview data suggest that students are not using this resource and instead are relying on the perception-based p-prim.

\section{Lenses dividing up the light}

Many students predicted that only the portion of the grid pattern corresponding to the location of the vision defect would be altered. One student's prediction is as follows:

Interviewer: "What do you think will happen to our grid pattern if the lens of the eye has a defect?" Student: "The grid will change."

Interviewer: "Okay - how do you think it might change?"

Student: "I believe that for most of the eye, it would still be like this [normal grid pattern], but some areas would have - you know, they'd be imperfect."

This student and many others used the resource that lenses only focus the light that enters them when they predicted that only a portion of the grid would change. Using this reasoning, the altered light from the defect only entered some of the lenses, so the others would not produce a distorted image. The activation of this resource enabled students to construct the idea that $a$ defect in the eye will only distort the part of the grid that is getting the light from the defect. For example, if the defect is that the top half of the lens is distorted then only half of the grid pattern will be affected. From a general perspective, this notion may come from our everyday experiences; we cannot see things that are outside of our range of vision. However, it may also be linked to other ideas that have been presented in the literature about how students understand lenses. An example could be the commonly held idea that when half of a lens is covered, half of the image will disappear ${ }^{7}$. Consistent with this idea, the student might believe that light from that half of the object can no longer enter the lens, and as such will not contribute to the produced image.

The previous excerpt was taken from the prediction phase. In fact, eight of 18 students made similar predictions. During the testing stage, the participants noted that more of the grid pattern changed than they had originally predicted. This was frequently explained by noting that a bigger aberration created a bigger distortion:

"Well, the harder you push [on the lens] the more deformed the shape of these small dots [of grid

pattern] - they go from circular to almost a dash shape. If you push hard enough, then eventually everything starts to get displaced."

This was also noted with other participants in previous phases of the project. The explanation that more deformation of a lens results in more distortion of the image could be the result of another resource, the p-prim more cause results in more effect.

\section{Light through lenses}

Throughout the protocol, students were asked to predict and explain the changes to the grid pattern as a result of a defect in the lens. This in many cases led to a discussion of the way that light moves through a lens. In fact, in 17 of the 18 interviews this discussion occurred, making it the most widely-used resource throughout the phase. Consider the following excerpt from one of the interviews:

Interviewer: "Why do you think that the grid pattern will change?"

Student: "If you have a defect [in the lens], it's going to change the way that the light comes out of it, so it would have an effect on these lenses [of array] and how it comes out of them."

In this circumstance, the student is clearly using the resource that light that enters a lens differently will focus differently. This same resource was also prominent in previous phases as students attempted to explain the changes that occurred in the grid pattern. To probe this resource more deeply during this phase, students were asked to draw to sketches of light through a convex lens. In the first sketch, the light rays entered the lens parallel to the optical axis. In the second sketch, however, light rays were coming into the lens at an angle to the optical axis. All of the students recognized that the first case would produce focused rays at some location on the optical axis. The second task, however, produced two distinctly different answers. One example drawing from each case can be seen in Figure 4. 

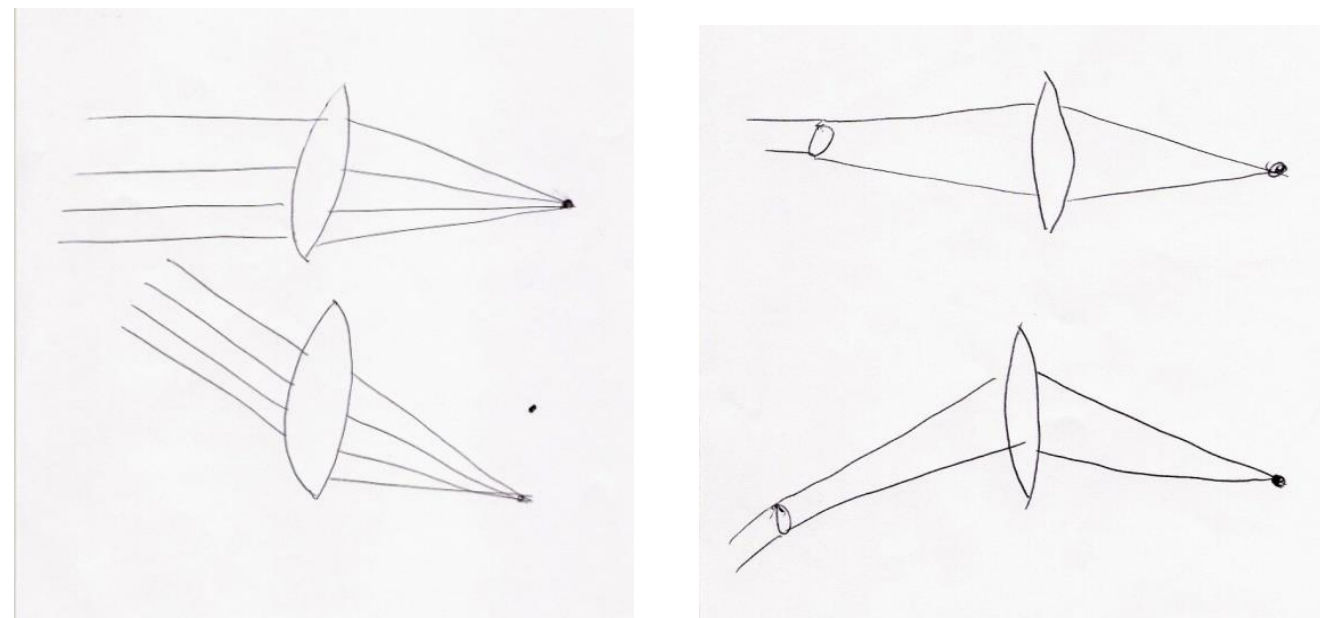

Figure 4 Two ideas about how light could focus through a lens

None of the students indicated, either in words or through their sketches, that the focal point would be at the exact same point. The idea of changing the way light enters a lens was not directly addressed during the provided experiences about the human eye and lenses; however, this resource had a very high frequency of use. This seems to suggest that this idea is in fact part of the more general phenomenological primitive (or p-prim) ${ }^{36}$ that $a$ change in part $A$ results in a change in part $B$, or more simply stated, propagation of changes.

\section{Light and Distance}

The participants in this phase of the study often discussed properties of light in terms of the distance to the light. Strongly exhibited was the common p-prim that closer is stronger ${ }^{35}$, which could lead to the facet that $c l o s e r$ is brighter. This led students to predict that the shape of the eye would affect the intensity of the image. As an example, one student predicted that because of the changing shape of the eye, the intensity of the grid pattern would change. When asked why, he responded simply "well, a flashlight doesn't look as bright at 20 feet as it does at 10 feet."

Another interesting response was how some students explained why the spacing of the grid pattern changed as the shape of the eye changed. As one student explained,

"If your light is really close - you have all of the light right here [the center of the lens], so your focal point is going to be pretty close too, because the light doesn't get very much. But if all your light comes from the whole direction - like they [light rays] are really far out [on the periphery of the lens] - then your focal point will be out further."

In this and other cases, the students seemed to be associating the spreading of light with the focal point. They described light that was close to the lens as entering mostly straight and at the center of the lens, while light that was farther away had time (or distance) to spread out and therefore hit the entire lens.

\section{Post-Instruction Groups - Interviews}

The fourth phase of the study dealt exclusively with students who were post-instruction in light, lenses, and basic geometric optics. Their instruction during a learning/teaching interview included a revision of our lesson based on the results of the previous phase. Because these students were post-instruction, they came to the group interviews with an extensive set of resources for the context of light and lenses. To probe their understanding, the initial questions focused on the function of the human eye, and produced the themes discussed below. All of the groups indicated that vision defects were dependent on the shape of the eye, and four of the five groups indicated without being prompted which defect corresponded to which eye shape.

\section{Light through Lenses}

The students who participated in the group interviews utilized their resources about how light travels through lenses multiple times throughout the course of the interview. Consider the following excerpt as an illustration.

Interviewer: "What do you think will happen to the grid pattern if I change the shape of the eye?" 
Student 1: "I think it may stay the same, as far as the structure of where the dots are. But they may get closer or farther, or the dots may change size also."

Interviewer: "Okay, why do you say that?"

Student 2: "If it's a nearsighted eye, the dots are going to get closer together because the light is going to be coming in more parallel compared to... like, the angle between the top one and how far the light is away is going to be ... the further away the light is, the shallower the angle is. So here is the angle like that [draws it coming into the lens at a steep angle], so this dot is going to be higher. But if you pull all the light away, the angle is going to be shallower, so they're all going to be closer together."

Student 3: "Yeah, based on the medium it goes through. Like they said, the angle is going through the medium, and based on the fraction, it'll come out of the lens."

As illustrated, students who participated in the group interviews used the idea of light travelling more frequently and more generally than any other of the previous participants. They also discussed the thickness of lenses in relationship to how light travels and the focal point of the lens. However, the propagation of changes p-prim that emerged in previous phases was not evident in this phase of the project.

The groups were also asked to perform the task of sketching light through lenses as was done in the earlier phases of the project. Every group indicated that the light would still focus if it entered from an angle, and that the focal point would shift in the same direction as the light entered (i.e. if the light entered the lens downward, the focal point would shift to below the original point). This is perhaps not surprising due to the fact that they had already studied light and lenses, and presumably were activating their resources appropriately in this context.

\section{Shape of the Eye and Image Focus}

As indicated above, all of the groups clearly stated that vision defects were a result of the shape of the eye and distance from the lens to the retina. The groups explained vision defects in terms of the person seeing a blurry object. As an example, consider the group discussion below.

Student 1: "The distance from [lens] to [retina] would be different from eye to eye. If you want it to be in focus correctly, like it wasn't a nearsighted eye or whatever. That'd be the difference between nearsighted and farsighted. Like if it ... it's supposed to focus back here [on the retina], but this [retina] is too far forward."

Student 2: "Yeah like, I'm pretty sure nearsighted means it focuses right here [in front of retina], so that you can't see far objects. And farsighted is back here [behind retina] so you can't see near objects."

These students were discussing where the proper focus of the image would be located with respect to the location of the retina. Interestingly, none of the groups activated the resource that the shape of the eye determines the image focus.

\section{Shape of the Eye and Image Size}

Unlike the previous resource, students did seem to rely heavily on the notion that the shape of the eye determines the image size. Three of the five groups predicted that the dots would change size when the shape of the eye was changed, and three groups also predicted that the overall size of the entire grid pattern would change. For example, the discussion from one group follows:

Interviewer: "What do you think will happen to the grid pattern if I change the shape of the eye?"

Student 3: "The lights wouldn't be like, they'd either be tinier or bigger than they should be."

Interviewer: "Okay - the lights themselves or the whole pattern?"

Student 3: "The whole pattern and the lights included."

Student 2: "Well, if you make [the eye] longer, probably from that distance the dots would spread out farther - the length between the dots would be farther.

And then after testing their predictions, the students noted:

Student 3: "yes, the pattern gets bigger as [the retina] gets closer ... and close up it's magnified, so it's so spread out that it's really hard to tell the brightness.

\section{E. Summary of Results from All Phases}

The results of the first phase indicated first and foremost that pre-instruction students have an inconsistent and incomplete understanding of how the human eye functions. Students were often unable to apply their model of the human eye to understand the physics of vision, and student knowledge of vision defects was limited. The large qualitative survey issued as the second part of the pilot study affirmed that even after minimal instruction in basic optics, students had a more coherent, correct, and consistent understanding of how the ocular system functions at a basic level. Each of these phases pointed to the need to develop the foundational concepts of light before moving on 
to the ocular system. As such, our learning materials were re-conceived to first provide the necessary foundational information (foundational material on basic geometric optics was given before moving on to vision and the eye).

Post-instruction, students were able to understand basic optics and the human eye. The concept introduction provided a much more consistent background for the participants, and was designed to provide them with some of the resources that they would need to understand vision and vision defects. During previous phases, students who did not have this concept introduction were very disinclined to progress forward with the physics of vision and vision defects. That type of reluctance from the participants did not surface during this phase. Presumably because of this concept introduction, the data obtained from the discussions provided a much richer set of data than did the previous phase. These contrasting experiences seem to verify that a basic understanding of light, lenses, and the eye is essential for the further understanding of vision and vision defects.

\section{CONCLUSIONS}

From the above analysis, it is evident that students do have a large number of resources of varying grain-size that they can use when constructing their understanding of the human eye and vision. Some resources, such as light moving through a lens, are exhibited by a large number of participants. Other resources are used less frequently, but are still important to study. The results also indicated that while most students have a large body of prior knowledge about the human eye and basic optics, much scaffolding is needed to facilitate the activation of appropriate resources and to associate them in meaningful ways. One example of scaffolding that seemed to help in this case was the drawing of light rays through a lens in order for them to think about what happened to the focal point. In many cases, this enabled students to think about how the grid pattern would shift. This and other scaffolding was included in subsequent versions of the learning materials to facilitate student understanding.

The participants who were post-instruction in light and optics from a traditional lecture course had activated a significantly different set of resources than students from previous phases. Whereas the students who were preinstruction tended to use more experiential knowledge, the post-instruction students used a considerable amount of textbook knowledge. Students on several occasions recited the thin-lens equation and referred to the image and object distances as variables. However, they were able to appropriately activate resources that allowed them to construct an understanding of the human eye and vision.

It should be noted that this study went on to examine whether students were able to apply their knowledge about light/optics and vision to understand a relatively new method of diagnosing vision defects called wavefront aberrometry. The results of that study are too extensive for inclusion here, and as such will be dealt with in a subsequent paper.

In summary, this study presents an analysis of what resources students use when constructing an understanding of the human eye and vision. Distinct phases of the study were analyzed in such a way to elicit the resources students used, but also so that comparisons could be made across all phases. In general both pre- and postinstruction students had a large body of resources about the human eye and vision, many of which are artifacts of their everyday experiences with vision. As would be expected, students have significantly fewer resources initially available to them about vision and vision defects. However, this study indicates that students are able to construct the necessary understanding through transfer and activation of resources when appropriate scaffolding is provided. Further, each phase of the study provided us with new insights into student understanding of light, optics, and vision that helped to shape and refine the learning materials.

As referenced several places in the text above, a set of research-based learning materials was developed from the results of this study. Those materials provide the introductory material on light and basic optics and follow a continuous progression from the idea of a pin hole to a single lens, and eventually to an optical system closely resembling the human eye. Those materials are freely available through the Kansas State University Physics Education Research Group's website: http://web.phys.ksu.edu/mmmm.

\section{REFERENCES}

1 B. Andersson and C Karrqvist, "Light and its properties: EKNA Report \#8", (Goteborgs University, Sweden, 1981).

2 B.F. Stead and R.J Osborne, "Exploring Students' Concepts of Light," Australian Science Teacher's Journal 26 (3), 84-90 (1980).

3 D. Langley, M. Ronen, and B.S. Eylon, "Light propagation and visual patterns: pre-instruction learners' conceptions," Journal of Research in Science Teaching 34, 399-424 (1997). 
A.B. Saxena, "The understanding of the properties of light by students in India," International Journal of Science Education 13, 283-289 (1991).

5 S. Bendall, I. Galili, and F. Goldberg, "Prospective elementary school teachers' prior knowledge about light," Journal of Research in Science Teaching 30, 1169-1187 (1993).

$6 \quad$ F. Goldberg and L.C. McDermott, "Student difficulties in understanding image formation by a plane mirror," The Physics Teacher 24, 472-480 (1986).

F. M. Goldberg and Lillian C. McDermott, "An investigation of student understanding of the real image formed by a converging lens or concave mirror," American Journal of Physics 55, 108-119 (1987). I. Galili, S. Bendall, and F. Goldberg, "The effects of prior knowledge and instruction on understanding image formation," Journal of Research in Science Teaching 30, 271-301 (1993).

9 B.S. Ambrose, P.S. Shaffer, R.N. Steinberg, and L.C. McDermott, "An investigation of student understanding of single-slit diffraction and double-slit interference," American Journal of Physics 67, 146-155 (1999).

10 D.J. Grayson, "Many rays are better than two," The Physics Teacher 33, 42-43 (1995).

11 L.C. McDermott and P.S. Shaffer, Tutorials in Introductory Physics. (Prentice Hall, Upper Saddle River, NJ, 2002).

12 K. Wosilait, P.R.L. Heron, P.S. Shaffer, and L.C. McDermott, "Development and assessment of a researchbased tutorial on light and shadow," American Journal of Physics 66, 906-913 (1998).

13 presented at the Fourth UNESCO Workshop on Active Learning in Optics and Photonics, Delhi, India, 2006 (unpublished).

14 Igal Galili and Amnon Hazan, "The effect of a history-based course in optics on students' views about science," Science and Education 10 (1-2), 7-32 (2001).

15 Philip Stephenson and Paul Warwick, "Using concept cartoons to support progression in students' understanding of light," Physics Education 37 (2), 135-141 (2002).

16 Xiangxi Chen, Jacob Huang, and Eddie Loh, "Computer-assisted teaching of optics," American Journal of Physics 55 (12), 1129-1133 (1987).

17 B.S. Eylon, M. Ronen, and U. Ganiel, "Computer simulations as tools for teaching and learning: Using a simulation environment in optics," Journal of Science Education and Technology 5 (2), 93-110 (1996). F. Goldberg and S. Bendall, "Making the invisible visible: A teaching/learning environment that builds on a new view of the physics learner," American Journal of Physics 63, 978-991 (1995).

Barrie W. Jones, "Optics - what to teach?," Physics Education November (513), 517 (1976).

Miky Ronen and Bat-Sheva Eylon, "To see or not to see: the eye in geometrical optics - when and how?," Physics Education 28, 52-59 (1983). about visual images," Physics Education 39 (3), 294-297 (2004). 224) (1991).

T. H. Edwards and et al., "Life science-related physics laboratory on geometrical optics," American Journal of Physics 43 (9), 764-765 (1975).

W. Bruce Mullin, "The working of the Human Eye III," Physics Education 1 (4), 276-278 (1966); W. Bruce Mullin, "The working of the Human Eye," Physics Education 1 (1), 34-38 (1966); W. Bruce Mullin, "The working of the Human Eye II," Physics Education 1 (2), 104-106 (1966).

5 Antti Arell and Samuli Kolari, "Experiments on a model eye," American Journal of Physics 46 (6), 613-614 (1978).

Giuseppe Colicchia and Hartmut Wiesner, "Measuring aberration of the eye with wavefront technology," Physics Education 41 (4), 307-310 (2006).

Physics Education Research Group Kansas State University, "Modern Miracle Medical Machines", in http://web.phys.ksu.edu/mmmm/ (2010).

8 Ufuk Dilek and Mehmet Sahin, "Investigating accommodation using eyes and lenses," Physics Education 48 (2), 194-198 (2013).

D. Kaltakci and A. Eryilmaz, "Context-based questions: optics in animal eyes," Physics Education 46 (3), 323-327 (2011).

Eric Brewe, Nancy J Pelaez, and Todd J Cooke, "From vision to change: educational initiatives and research at the intersection of physics and biology," CBE-Life Sciences Education 12 (2), 117-119 (2013).

1 David Hammer, "More than misconceptions: Multiple perspectives on student knowledge and reasoning, and an appropriate role for education research," American Journal of Physics 64 (10), 1316 (1996). 

Education Research Supplement 68 (S1), S52-S59 (2000).

33 D. Hammer and Andrew Elby, "On the Form of a Personal Epistemology", in Personal Epistemology: The Psychology of Beliefs about Knowledge and Knowing, edited by B.K. Hofer and P.R. Pintrich (Erlbaum, Mahwah, NJ, 2002), pp. 169-190.

34 A.A. diSessa, "Knowledge in Pieces", in Constructivism in the computer age, edited by G. Forman and P.B. Putfall (Lawrence Erlbaum, Hillsdale, NJ, 1988).

35 A. diSessa, "Toward an Epistemology of Physics," Cognition and Instruction 10 (2-3), 105-225 (1993).

36 A. diSessa and Bruce L. Sherin, "What changes in conceptual change?," International Journal of Science Education 20 (10), 1155-1191 (1998).

37 M. Bassok, "Transfer of domain-specific problem-solving procedures," Journal of Experimental Psychology: Learning, Memory and Cognition, 522-533 (1990); Z. Chen and M.W. Daehler, "Positive and negative transfer in analogical problem solving," Cognitive Development 4, 327-344 (1989); $\quad$ Stephen K. Reed and Cheryl A. Bolstad, "Use of examples and procedures in problem solving," Journal of Experimental Psychology: Learning, Memory, and Cognition 17 (4), 753-766 (1991).

38 J. Lave and E. Wenger, Situated Learning: Legitimate peripheral participation. (Cambridge University Press, Cambridge, 1991).

39 J.E. Lobato, Ph.D. Dissertation, University of California, Berkeley, 1996.

40 J.D. Bransford and D. Schwartz, "Rethinking transfer: A simple proposal with multiple implications," Review of Research in Education 24, 61-100 (1999); D. Schwartz, J.D. Bransford, and D. Sears, "Efficiency and Innovation in Transfer", in Transfer of Learning from a Modern Multidisciplinary Perspective, edited by Hose P. Mestre (Information Age, Greenwich, CT, 2005).

41 N. S. Rebello, Dean A. Zollman, A.R. Allbaugh, Paula V. Engelhardt, K.E. Gray, Zdeslav Hrepic, and Salomon F. Itza-Ortiz, "Dynamic Transfer: A Perspective from Physics Education", in Transfer of Learning from a Modern Multidisciplinary Perspective, edited by Hose P. Mestre (Information Age, Greenwich, CT, 2005).

42 Dyan L. McBride, Sytil Murphy, and Dean A. Zollman, "A lens to demonstrate accommodation in the focusing of the human eye ", in Winner of AAPT Apparatus Competition (Portland, Oregon, 2010). Paula V. Engelhardt and Edgar G. Corpuz, presented at the Physics Education Research Conference, Madison, WI., 2003 (unpublished).

44 K. Charmaz, Constructing Grounded Theory: A practical guide through qualitative analysis. (Sage, Thousand Oaks, 2006); J. Corbin and A. Strauss, "Grounded theory method: procedures, canons, and evaluative criteria," Qualitative Sociology 13 (1), 3-21 (1990); $\quad$ A. Strauss and J. Corbin, Basics of Qualitative Research: Grounded Theory Procedures and Techniques. (Sage, Newbury Park, 1990); A. Strauss and J. Corbin, Handbook of Qualitative Research. (Sage, Thousand Oaks, 1994). F Marton, "Phenomenography - a research approach to investigating different understandings of reality," Journal of Thought 21, 28-49 (1986).

46 Dyan McBride, Dissertation, Kansas State University, 2009. 